\title{
Effects of Estradiol and Progesterone on Voltage-Gated Calcium and Potassium Conductances in Rat CA1 Hippocampal Neurons
}

\author{
M. Joëls and H. Karst \\ Institute for Neurobiology, Amsterdam Graduate School "Neurosciences," 1098 SM Amsterdam, The Netherlands
}

In this study we recorded voltage gated $\mathrm{Ca}$ and $\mathrm{K}$ conductances with patch electrodes in hippocampal slices from female rats, which were ovariectomized (OVX) 1 week before the experiment. One experimental group was primed with estradiol at day 3 and 4 after OVX and received progesterone $4 \mathrm{hr}$ before the start of the experiment. The second group was treated with estradiol at day 3 and 4 , but received vehicle at the day of the experiment. The third group was not treated with hormones (only vehicle injections). We observed that the amplitude of both sustained and transient $\mathrm{Ca}$ currents were significantly enhanced in CA1 pyramidal neurons recorded in tissue from estradiol primed rats receiving progesterone when compared to the nontreated OVX controls; without estradiol priming $\mathrm{Ca}$ current amplitudes were small. Current amplitudes in tissue from rats treated with estradiol only, were at intermediate values. The voltage for half-maximal steady state inactivation of the transient $\mathrm{Ca}$ current was at a less negative value for the estradiol/progesterone treated group in comparison to the OVX controls. Input resistances of the cells, and voltage or kinetic properties of the currents as recorded under these conditions were comparable for the three groups. Characteristics of two voltage gated $K$ conductances, that is, the transient $I_{A}$ and the delayed rectifier, displayed no consistent differences for the three experimental groups. We conclude that long-term modulation of estradiol and progesterone levels alters the $\mathrm{Ca}$ but not the $\mathrm{K}$ currents that were tested in CA1 pyramidal neurons. These alterations may be linked to steroid-induced morphological changes in dendrites of CA1 pyramidal cells.

[Key words: estradiol, progesterone, $\mathrm{Ca}$ current, $\mathrm{K}$ current, ovariectomy, CA1 area, hippocampus, patch-clamp recording, rat]

The rat female sex steroid hormones estradiol and progesterone can pass the blood brain barrier and bind to discretely localized intracellular receptors in the brain (Pfaff and Keiner, 1973; Parsons et al., 1982; Cintra et al., 1986; Loy et al., 1988). These receptors are highly expressed in rat hypothalamus, preoptic area and some limbic structures (Pelletier et al., 1988; Simerly et al.,

\footnotetext{
Received Apr. 6, 1994; revised Dec. 30, 1994; accepted Jan. 19, 1995.

We thank $H$. van Dieten and G. Advocaat for surgical assistance, E. Velzing for assistance with histology, G. Faas and W. Wadman for assistance with data analysis, and E. R. de Kloet and W. Wadman for fruitful discussions. H.K. was supported by Grant $900-553-028$ from NWO.

Correspondence should be addressed to Marian Joëls, Institute for Neurobiology, University of Amsterdam, Kruislaan 320, 1098 SM Amsterdam, The Netherlands.

Copyright (c) 1995 Society for Neuroscience $0270-6474 / 95 / 154289-09 \$ 05.00 / 0$
}

1990; Hagihara et al., 1992). Pyramidal neurons in the hippocampal CA1 area contain intracellular receptors for progesterone and, to a lesser degree, for estradiol (Pelletier et al., 1988; Hagihara ct al., 1992). In addition to these intraccllular receptors which act as transcription factors on the genome, the presence of membrane receptors for the sex hormones has been postulated; membrane receptors are thought to mediate rapid actions of estradiol, progesterone, and their metabolites (for reviews, see Majewska, 1992; Paul and Purdy, 1992; Simmonds, 1992).

The presence of intracellular receptors for progesterone and estradiol in CAl pyramidal neurons raised the question if and how the female sex hormones affect characteristics of these neurons. Recently, a series of experiments by McEwen and coworkers showed that treatment of ovariectomized (OVX) rats with estradiol and progesterone increased the density of dendritic spines on distal dendrites of CA1 pyramidal neurons when compared to the neurons in tissue from untreated OVX rats (Gould et al., 1990). Maximal differences were observed 2-3 d after estradiol and 2-6 hr after progesterone treatment (Woolley and McEwen, 1993). Differences in hippocampal dendritic spine density were also observed during various stages of the estrous cycle (Woolley et al., 1990; Woolley and McEwen, 1992). The steroid dependency of dendritic spine density may be linked to changes of intrinsic membrane properties and synaptic responses of CA1 neurons. In accordance with the latter, Wong and Moss (1992) reported that $2 \mathrm{~d}$ after treatment with estradiol the duration of the excitatory postsynaptic potential and repetitive firing induced by synaptic stimulation were enhanced compared to neurons in untreated OVX control tissue.

In the present study we examined if modulation of estradiol and progesterone levels in OVX rats, known to alter the hippocampal dendritic spine density, affects the characteristics of voltage gated ion currents, recorded with patch electrodes in the soma of CA1 pyramidal neurons. In one series of experiments we focused on two $\mathrm{Ca}$ conductances, that is, a rapidly inactivating, low-threshold current which is at least partly generated in distal dendrites (Karst et al., 1993a) and a high-threshold current which displays very litule voltage dependent inactivation. In another series we examined two $K$ conductances, that is, the transient $I_{\mathrm{A}}$ and the delayed rectifier. The $\mathrm{Ca}$ and $\mathrm{K}$ currents were recorded in three experimental groups: the first group consisted of OVX rats which received estradiol at 3 and $4 \mathrm{~d}$ after OVX and progesterone at $4 \mathrm{hr}$ before the start of the experiment. The second group was only treated with estradiol, while the third group received no steroid treatment. The steroid doses and application scheme were selected to evoke maximal effects on hippocampal dendritic spine density. Input resistances, current amplitude and voltage or kinetic properties of the $\mathrm{Ca}$ and $\mathrm{K}$ conductances were compared for the three experimental groups. 


\section{Materials and Methods}

Thirty-eight virgin female Wistar rats (Harlan TNO, Zeist; ca. $150 \mathrm{gm}$ ) were used for the study. The rats were housed in an animal house with alternating light-dark cycle (8:00 A.M. lights on, $12 \mathrm{hr}$ cycle) and received food and water ad libitum. All rats were ovariectomized (OVX) 1 week before the experiment, under ether anaesthesia. Three experimental groups were discerned. (1) Nine animals received a subcutaneous injection with estradiol benzoate $(10 \mu \mathrm{g} / 0.1 \mathrm{ml}$ peanut oil) both at 3 and $4 \mathrm{~d}$ after OVX and with progesterone $(500 \mu \mathrm{g} / 0.1 \mathrm{ml}$ peanut oil) at $4 \mathrm{hr}$ before the start of the experiment (decapitation). (2) Ten animals were only treated with estradiol and received a peanut oil injection 4 $\mathrm{hr}$ before the experiment. (3) Thirteen animals received only peanut oil injections, at 3 and $4 \mathrm{~d}$ after OVX and $4 \mathrm{hr}$ before the experiment. Approximately half of the experiments were performed in a double blind fashion. The results from the double blind experiments did not differ from the remaining data. The selected hormone replacement was nearly the same as the one described by Gould et al. (1990). In a followup study we also examined six animals which received progesterone at $4 \mathrm{hr}$ before the start of the experiment, but were not subjected to prior estradiol treatment. Estradiol benzoate and progesterone were supplied by Organon Int. (Oss, The Netherlands).

At the day of the experiment the rat was placed in a novel environment (clean cage) 30-60 min before decapitation, thus introducing a mild stress. The ensuing (moderately high) corticosteroid levels will mask possible variance in corticosteroid baseline levels between rats the hour before sacrifice, and result in occupation of most of the mineralocorticoid and a considerable part of the glucocorticoid receptors in all experimental animals, at the start of the experiment (Reul et al., 1987). A comparable corticosteroid receptor occupation in hippocampal tissue between groups is important, since recent studies show that the degree of corticosteroid receptor activation in part determines $\mathrm{Ca}$ current amplitudes (Karst et al., 1994). The rats were decapitated under ether anesthesia and trunk blood was collected for determination of plasma estradiol, progesterone and corticosterone with a radioimmunoassay. The brain was dipped in cold $\left(4^{\circ} \mathrm{C}\right)$ carbogenated $\left(95 \% \mathrm{O}_{2}, 5 \% \mathrm{CO}_{2}\right)$ artificial cerebrospinal fluid (ACSF) of the following composition, in mM: $124 \mathrm{NaCl}, 3.5 \mathrm{KCl}, 1.25 \mathrm{NaII}_{2} \mathrm{PO}_{4}, 1.5 \mathrm{MgSO}_{4}, 2 \mathrm{CaCl}_{2}, 25 \mathrm{NaICO}_{3}$, 10 glucose, $\mathrm{pH} 7.4, \sim 300 \mathrm{mOsm}$. The hippocampus was quickly dissected. One lobe was kept in $4 \%$ paraformaldehyde in $0.1 \mathrm{~m}$ phosphate buffer with $15 \%$ picric acid for later histological analysis, the other lobe was cut in transverse slices $(120 \mu \mathrm{m})$ on a tissue chopper. Hippocampal slices were kept at room temperature in a holding chamber with carbogenated ACSF. One slice at a time was transferred to a recording chamber, submerged and continuously perfused $(2 \mathrm{ml} / \mathrm{min})$ with warm $\left(32^{\circ} \mathrm{C}\right)$ carbogenated ACSF.

Hippocampal pyramidal CA1 neurons were selected for recording with a light microscope (Nikon 104), using a magnification of $400 x$, that is, $40 \times$ water immersion objective and $10 \times$ ocular. With a patch pipette (pulled on a Sutter micropipette puller from $1.5 \mathrm{~mm}$ outer diameter borosilicate glass; $1.5-3.0 . \mathrm{M} \Omega$ ) the selected cell was approached. Positive pressure ensurcd that the tip of the clectrode was kept clean and that the surface of the membrane was freed from surrounding neuropil (based on the method of Edwards et al., 1989) When the tip of the electrode was placed on the membrane, a gigaseal was established by application of light suction; additional suction resulted in the whole cell recording configuration. For the recording of $\mathrm{Ca}$ currents, the pipette solution consisted of (in mM) $100 \mathrm{CsF}, 0.5 \mathrm{CaCl}_{2}, 2$ $\mathrm{MgCl}_{2}, 2 \mathrm{MgATP}, 0.1 \mathrm{NaGTP}, 10$ HEPES, 10 EGTA, 20 creatine phosphate, $50 \mathrm{U} / \mathrm{ml}$ creatine phosphokinase, 0.1 albumin, $20 \mathrm{TEA} \mathrm{Cl}, \mathrm{pH}$ $7.4,300 \mathrm{mOsm}$. This solution was frozen and kept on ice during the day of the experiment. Furthermore, $0.5 \mu \mathrm{M}$ tetrodotoxin was added to the extracellular ACSF to block Na currents; $\mathrm{K}$ conductances were blocked by extracellular addition of $10 \mathrm{~mm}$ tetraethylammonium $\mathrm{HCl}$, $5 \mathrm{~mm}$ of 4 -aminopyridine, and $5 \mathrm{mM} \mathrm{CsCl}$. When we recorded $\mathrm{K}$ conductances the pipette solution consisted of (in mM) $140 \mathrm{KF}, 2 \mathrm{MgCl}_{2}$, $1 \mathrm{CaCl}_{2}, 10$ HEPES, 10 EGTA, pH 7.4. TTX $(0.5 \mu \mathrm{M})$ tetrodotoxin was added to the ACSF.

Whole cell currents were measured under voltage-clamp conditions using a Biologic RK300 amplifier. Data was collected with an Atari computer, at $\mathrm{I}$ and $5 \mathrm{kHz}$ sampling rate (of the computer) for $\mathrm{Ca}$ and $\mathrm{K}$ currents, respectively. We used an acquisition and analysis program developed in-house. Voltage step protocols were generated by the acquisition program. Each cell was subjected to the same sequence of timed voltage protocols, as described elsewhere (Karst et al., 1993b; Karst et al., 1994). Activation of Ca currents was recorded at 5, 10, and
$20 \mathrm{~min}$., and inactivation properties immediately and $15 \mathrm{~min}$. after establishing the whole cell configuration. We observed that, although $\mathrm{Ca}$ currents were immediately visible, the amplitude typically increased over the first 5--7 min, next stabilized for about $10 \mathrm{~min}$ and then gradually declined (but usually still amounted to $>70 \%$ of the maximal amplitude after $20 \mathrm{~min}$ ). All data about Ca current activation presented in this article were collected at 10 min after the whole cell configuration was established; we describe the inactivation properties observed after 15 min. Activation of $\mathrm{K}$ currents was recorded at 5 and $15 \mathrm{~min}$ and inactivation immediately after and $10 \mathrm{~min}$ after breaking into the cell; we here describe the activation properties observed after 5 min and inactivation of $\mathrm{K}$ current after $10 \mathrm{~min}$.

Single exponential functions were fitted to the inactivation phase of the transient inward $\mathrm{Ca}$ current and the first $100 \mathrm{msec}$ of the outward $\mathrm{K}$ current $I_{\mathrm{A}}$. The same least-square minimization algorithm was used to estimate the Boltzmann curves for steady-state inactivation of the transient $\mathrm{Ca}$ and $\mathrm{K}$ currents. Routinely, correction for linear leak-current, as estimated from sequential depolarizing and hyperpolarizing voltage steps of $5 \mathrm{mV}$ and $50 \mathrm{msec}$ duration at holding potential, was performed for both $\mathrm{K}$ currents and $\mathrm{Ca}$ currents (see Fig. $1 A$ ). Since patch-clamp recording in slices with an upright microscope, as we used in the present study, introduces relatively large capacity transients we also corrected for the capacity. Thus, for each cell the capacity transient for a voltage step from -130 to $-90 \mathrm{mV}$ (where no voltage gated ion currents are activated) was fitted with two time constants (typically around 3 and $15 \mathrm{msec}$ ). These time constants were used to calculate capacity transients for all voltage steps; the Ca currents were then corrected for these transients. Current properties were not basically altered by these correction procedures (see Fig. 1A). Series resistance was not compensated, justified by the combination of a low access resistance (ca. $4 \mathrm{M} \Omega$ ) and small current amplitudes (1-2 nA).

Statistical analysis of the differences between the various experimental groups was performed by a one-way ANOVA, followed by a post hoc unpaired Student's $t$ test $(p<0.05)$.

\section{Results}

\section{Ca currents}

Inward currents were activated in CAl pyramidal neurons by a 200 msec depolarizing step, preceded by a 3 sec hyperpolarizing pulse at $-130 \mathrm{mV}$, from a holding potential of $-65 \mathrm{mV}$ (see Figs. 1, 2). The depolarizations ranged from -100 to $20 \mathrm{mV}$, applied with increments of $10 \mathrm{mV}$ between successive (interval, $10 \mathrm{sec}$ ) depolarizations. After correction for linear leak conductance, current traces displayed little outward components (see Fig. 1A). Given the fact (1) that these currents were observed in the presence of extracellularly present tetraethylammonium, 4-aminopyridine, cesium, and TTX and with cesium in the pipette and (2) that the currents were previously shown to be effectively blocked by $\mathrm{Ni}$ (Karst et al., 1993a) we assumed that the inward currents represent voltage-activated $\mathrm{Ca}$ currents. In addition, we presently observed that the inward currents are sensitive to $25 \mu \mathrm{M} \mathrm{Cd}(n=3)$; higher doses of $\mathrm{Cd}(1 \mathrm{mM} ; n=3)$ almost completely blocked both the transient and sustained phase of the currents (see Fig. $1 B$ ). In the presence of $1 \mathrm{mM} \mathrm{Cd}$, voltage steps to $0,+10$, or $20 \mathrm{mV}$ in some cases evoked small outward currents; the amplitude of these outward currents amounted to $<25 \%$ of the maximal inward current evoked in the same cell. As argued elsewhere (Karst et al., 1993a), the outward currents may be residual $\mathrm{K}$ currents due to incomplete block of distal $\mathrm{K}$ channels, or currents carried by cesium.

As illustrated in Figures 1 and 2, and as described in previous reports (Karst et al., 1993a, 1994), the Ca current evoked by this voltage protocol displayed a transient and a sustained phase. The transient phase was subject to voltage dependent inactivation. This was particularly apparent when the potential of the $3 \mathrm{sec}$. prepulse was varied between -130 and $-70 \mathrm{mV}$. The voltage dependency of the inactivation could be described with the Boltzmann equation, $g(V) / g_{\max }=1 /\left[1+\exp \left\{\left(V-V_{\mathrm{H}}\right) / V_{\mathrm{c}}\right)\right]$, 
A

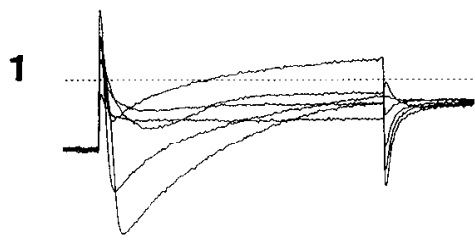

2

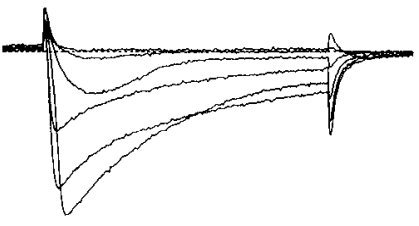

3

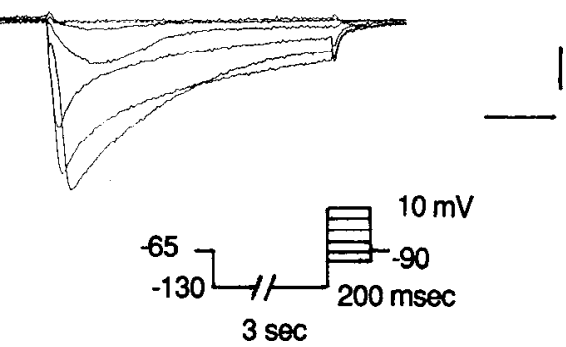

B
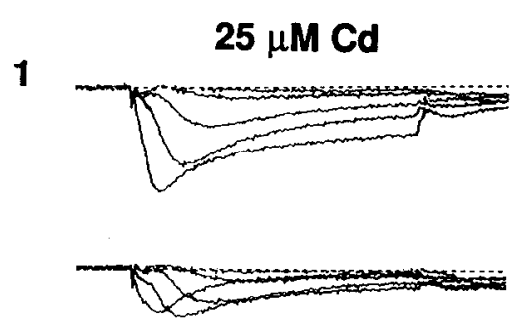

$1 \mathrm{mM} \mathrm{Cd}$

2
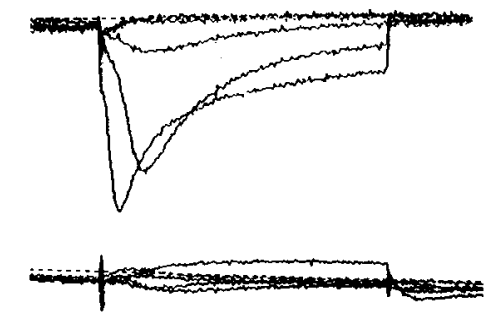

Figure 1. Al, Voltage steps $(200 \mathrm{~ms})$ to $-90,-70,-50,-30,-10$, and $10 \mathrm{mV}$ preceded by a hyperpolarizing prepulse $(3 \mathrm{sec})$ at $-130 \mathrm{mV}$ from a holding potential of $-65 \mathrm{mV}$ evoked inward currents in CA1 pyramidal cells of adult rats, as recorded in the whole cell configuration in hippocampal slices $\left(32^{\circ} \mathrm{C}\right)$. The traces were subsequently corrected for leak conductance, as established from $5 \mathrm{mV}$ de- and hyperpolarizing voltage steps of $50 \mathrm{msec}$ duration $(A 2)$. Finally, the capacity transient introduced by the fluid column around the pipette for the current evoked by a voltage step to $-90 \mathrm{mV}$ (where no voltage-dependent currents are activated) was fitted with two exponentials. These values were used to estimate the capacity transients for the remaining voltage steps; the traces corrected for the capacity transient are shown in $A 3$. The inset shows the voltage protocol. $B I$, Currents evoked by the voltage protocol (except for the voltage step to $10 \mathrm{mV}$ ) and corrected as described in $A$ under control conditions (upper traces) and in the presence of $25 \mu \mathrm{M}$ Cd (lower traces). B2, Inward currents recorded in another CAl neurons before (upper) and after addition of $1 \mathrm{~mm} \mathrm{Cd}$ (lower traces). Calibration: $50 \mathrm{msec}, 0.5 \mathrm{nA}$. where $g(V) / g_{\max }$ is the relative conductance at membrane potential $V, V_{\mathrm{H}}$ is the voltage of half-maximal inactivation and $V_{\mathrm{C}}$ is proportional to the slope of the curve at $V_{\mathrm{H}}$. For the neurons in slices from OVX rats, the $V_{\mathrm{H}}$ was around $-110 \mathrm{mV}$ (see Table 1). When the prepulse potential was set at $-65 \mathrm{mV}$ (i.e., equivalent to the holding potential), the transient phase of the $\mathrm{Ca}$ current was fully inactivated; with this protocol, a sustained $\mathrm{Ca}$ current was observed which activated around $-40 \mathrm{mV}$ and peaked at $-10 \mathrm{mV}$. This current, with little voltage- (though possibly still $\mathrm{Ca}$-) dependent inactivation will be referred to as the $I_{\mathrm{Ca}, \mathrm{ni}}$. The decaying phase $\left(\tau_{\mathrm{ni}}\right)$ was fitted with a single exponential function, for currents evoked by a depolarizing step to $-10 \mathrm{mV}$. Subtraction of the $I_{\mathrm{Ca}, \mathrm{mi}}$ from the overall $\mathrm{Ca}$ currents yielded inward currents which displayed strong voltage-dependent inactivation $\left(I_{\mathrm{Ca}, \mathrm{i}}\right)$. The $I_{\mathrm{Ca}, \mathrm{i}}$ activated around $-70 \mathrm{mV}$ and peaked between -50 and $-40 \mathrm{mV}$. The time constant for the decay $\left(\tau_{i}\right)$ was fitted with a single exponential function, for currents evoked by a voltage step to $-60 \mathrm{mV}$.

As shown in Table 1 , most cells in all three experimental groups displayed clear inward currents; the number of cells showing no appreciable currents (maximal amplitude $<0.2 \mathrm{nA}$ ) was not clearly different for the experimental groups. Figure 2 illustrates that the amplitude of the $I_{\mathrm{Ca}, \mathrm{i}}$ was increased in tissue from OVX rats treated with estradiol and progesterone, when compared to the tissue from the OVX controls. The increase was significant for currents evoked by depolarizations to -50 , $-40,-10$, and $0 \mathrm{mV}$ (Fig. 3A). Treatment with estradiol alone was not sufficient to increase the $I_{\mathrm{Ca}, \mathrm{i}}$ amplitude. At all potentials, $I_{\mathrm{Ca}, \mathrm{i}}$ for the estradiol treated group was similar to the OVX controls, while at $-50,-10$ and $0 \mathrm{mV}, I_{\mathrm{Ca}, \mathrm{i}}$ in estradiol treated rats was significantly smaller than in the estradiol/progesterone treated group. In addition to the estradiol/progesterone induced change in $I_{\mathrm{Ca}, \mathrm{i}}$ amplitude, the $V_{\mathrm{H}}$ for voltage dependent inacti- vation was affected. Yet, after treatment with estradiol and progesterone $V_{\mathrm{H}}$ was at a significantly more positive potential than in the OVX controls (see Table 1). Input resistance, as recorded under these conditions, the $\tau_{\mathrm{i}}$ and the slope factor $V_{\mathrm{C}}$ were not different for the three experimental groups.

Treatment with estradiol/progesterone also increased the amplitude of the $I_{\text {Ca,ni }}$ (see Figs. 2, 3B). Currents induced by voltage steps to $-40,-30$, or $-20 \mathrm{mV}$ were significantly enhanced compared to the OVX controls. Estradiol only induced intermediate currents which, with the exception of currents observed at $-40 \mathrm{mV}$, did not differ significantly from either the OVX controls or the tissue treated with estradiol and progesterone. The time constant for the decay was around $100 \mathrm{msec}$ for voltage steps to $-10 \mathrm{mV}$ and did not display steroid dependency (see Table 1).

We wondered if the observed progesterone-dependent increase of Ca current amplitude required prior estradiol treatment. In a follow-up series of experiments we therefore studied $\mathrm{Ca}$ currents in OVX rats which received vehicle treatment at day 3 and 4 , and progesterone at the day of the experiment. Eleven out of 14 neurons (recorded in slices from six animals) displayed clear Ca currents (maximal amplitude $>0.2 \mathrm{nA}$ ). As shown in Figure 4, the averaged amplitudes of both the $I_{\mathrm{Ca}, \mathrm{i}}$ and $I_{\mathrm{Ca}, \mathrm{ni}}$ were small: the maximal amplitude of the $I_{\mathrm{Ca}, \mathrm{i}}$ and $I_{\mathrm{Ca}, \mathrm{ni}}$ amounted to only $-0.51 \pm 0.09 \mathrm{nA}$ and $-0.20 \pm 0.06 \mathrm{nA}$, respectively, as compared to $-1.30 \pm 0.19$ and $-0.47 \pm 0.08 \mathrm{nA}$ observed in tissue of estrogen primed, progesterone treated rats. The voltage dependency shown in the $I-V$ relationship and the $V_{\mathrm{H}}$ for inactivation $(-113.6 \pm 1.7 \mathrm{mV})$ for rats only treated with progesterone resembled the values for the untreated OVX rats observed in the first series of experiments, rather than the properties of the estrogen-primed progesterone treated group. 


\section{OVX}
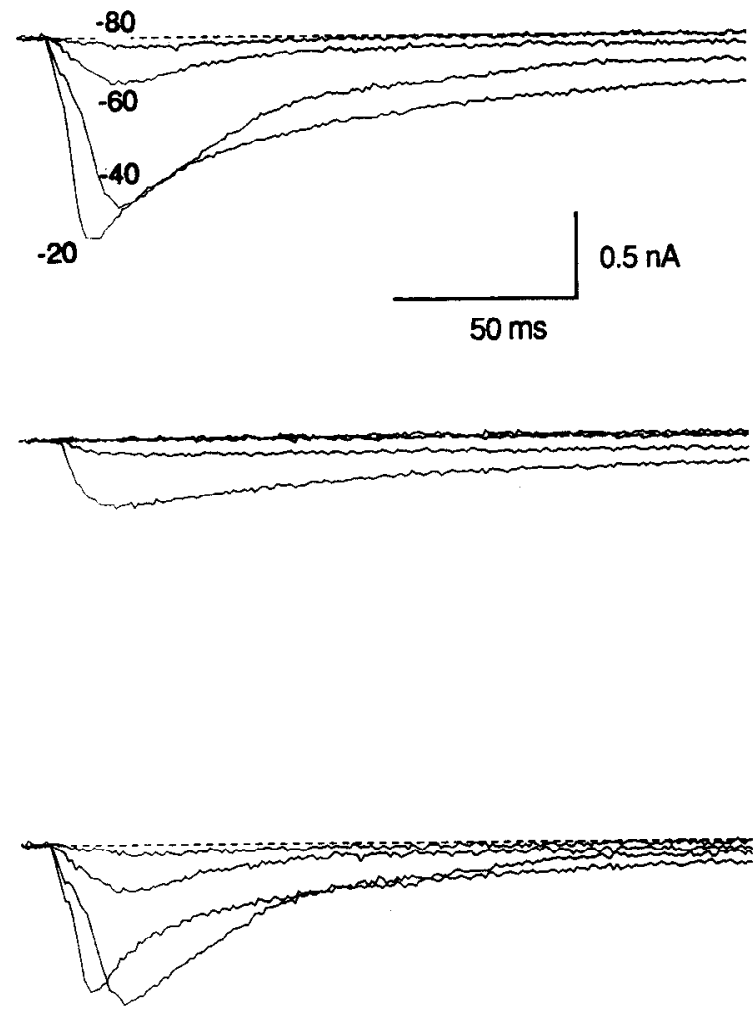

OVX/E / P
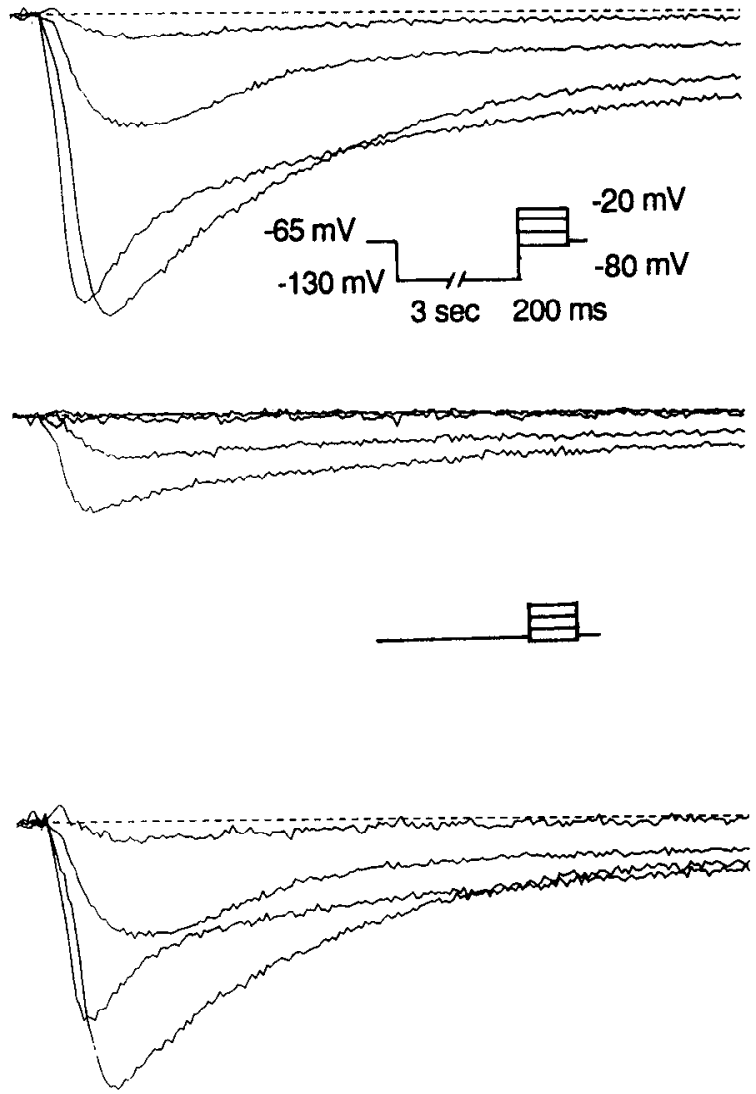

Figure 2. Typical Ca currents as recorded in a CA1 pyramidal cell in slices from an ovariectomized (OVX) female rat (left, upper panel) and an OVX rat treated with estradiol and progesterone (right, upper panel). The Ca currents display a transient and a sustained phase. Currents were induced by depolarizing voltage steps $(-100$ to $20 \mathrm{mV}$ ), with a $3 \mathrm{sec}$ prepulse at $-130 \mathrm{mV}$ and holding potential at $-65 \mathrm{mV}$ (see upper inset on the right for voltage protocol). Only currents induced by depolarization to $-80,-60,-40$, and $-20 \mathrm{mV}$ are depicted. When the depolarizations were applied directly from the holding potential (middle), only inward currents with little voltage dependent inactivation were observed $\left(I_{\text {Ca.tii }}\right)$. Subtraction of these currents from the overall $\mathrm{Ca}$ currents yielded predominantly transient Ca currents $\left(I_{\mathrm{C}}\right.$, lower panel $)$. Currents were corrected for linear capacitive transients and leak conductance. In this example, the transient Ca current recorded in tissue from the OVX rat treated with estradiol and progesterone was enhanced when compared to the untreated control.

\section{K currents}

Outward $\mathrm{K}$ currents were activated in CA1 pyramidal neurons by depolarizing steps of $200 \mathrm{msec}$, preceded by a $100 \mathrm{msec}$ hyperpolarizing pulse at $-130 \mathrm{mV}$. The depolarizing steps ranged from -60 to $0 \mathrm{mV}$, with an increment of $10 \mathrm{mV}$ between successive steps. The holding potential was at $-65 \mathrm{mV}$. As shown in Figure 5 (top), a transient and sustained phase of the outward current could be discerned. The transient outward current displayed a marked voltage dependent inactivation, which was clearly observed when the prepulse potential was varied between $-130 \mathrm{mV}$ and $-70 \mathrm{mV}$ (data not shown). The voltage dependency was described by a Boltzmann equation, as described above. The $V_{\mathrm{H}}$ for inactivation observed in the group of OVX control rats was around $-100 \mathrm{mV}$ (Table 2). By holding

\section{Table 1. General cell characteristics (Ca-currents)}

\begin{tabular}{lcrr} 
& OVX & OVX/E & OVX/E/P \\
\hline$R_{\text {in }}$ (in $\mathrm{M} \Omega$ ) & $100.0 \pm 10.4$ & $122.1 \pm 18.0$ & $105.5 \pm 16.1$ \\
$\tau_{i}$ (at $-60 \mathrm{mV}$; in msec) & $30.9 \pm 3.3$ & $30.1 \pm 2.4$ & $29.7 \pm 2.0$ \\
$\tau_{\text {ni }}$ (at $-10 \mathrm{mV}$; in msec) & $99.2 \pm 9.5$ & $107.1 \pm 8.8$ & $99.1 \pm 8.5$ \\
$V_{\mathrm{H}}$ inact. (in mV) & $-110.3 \pm 2.0$ & $-108.4 \pm 1.5$ & $-102.4 \pm 1.8^{*}$ \\
$V_{\mathrm{C}}$ inact. (in mV) & $11.1 \pm 0.8$ & $9.9 \pm 0.5$ & $10.1 \pm 0.7$ \\
$n, m(N)$ & $14,4(9)$ & $14,3(6)$ & $11,3(5)$
\end{tabular}

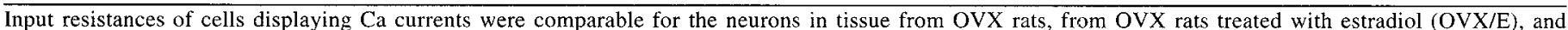

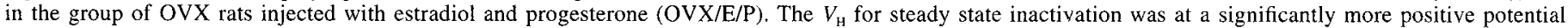

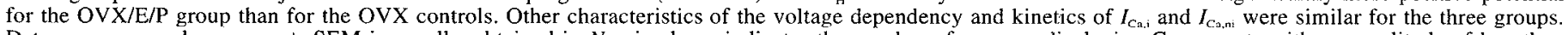

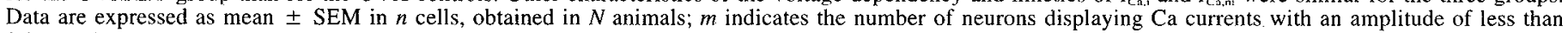
$0.2 \mathrm{nA}$; these were not included in the analysis. Statistical analysis was as described in Material and Methods. 
A

ICa,i B ICa,ni


- OVX

nA

O OVX/E

$\square$ OVX/E/P

Figure 3. Current-voltage relationship for the Ca currents obtained by the subtraction as described in Figure $2\left(I_{C a i}\right.$ in $\left.A\right)$ and the sustained Ca current $\left(I_{C a, n i}\right.$ in $B$ ). For each voltage, symbols represent the average \pm SEM. Solid circles are the values for the OVX controls group (14 cells), open circles for the OVX rats treated with estradiol $(14$ cells), while the squares represent the mean for the OVX treated with estradiol and progesterone $(11$ cells). For each voltage, the currents were tested with an ANOVA followed by an unpaired $t$ test. $\star$ indicates significant $(p<$ 0.05 ) differences with the OVX control and * with the estradiol treated group.

the cell for $75 \mathrm{msec}$ at $-65 \mathrm{mV}$ betwecn the hypcrpolarizing prepulse and the depolarizing step (see inset in Fig. 5, middle) the transient outward current could be fully inactivated, showing the sustained current in isolation. Subtraction of the sustained current from the overall $\mathrm{K}$ current yielded the transient outward current. As argued in previous reports (Spigelman et al., 1992; Karst et al., 1993b), the transient outward K current resembles the $I_{\mathrm{A}}$, while the sustained current is similar to the delayed rectifier described in other preparations and with other techniques.

Figure 6 represents the averaged amplitudes for $I_{\mathrm{A}}$ and the delayed rectifier $I_{\mathrm{K}}$, for voltage steps to $-30,-20,-10$, and 0 $\mathrm{mV}$. No significant differences were observed between the three experimental groups, although for all voltages currents in the estradiol treated group were on average relatively large. The input resistances for the three groups were comparable (see Table 2). The inactivation properties of the $I_{\mathrm{A}}$, that is, $V_{\mathrm{H}}$ and $V_{C}$, displayed no steroid dependency. This was also observed with respect to the time constant for the decay, which was obtained by fitting currents evoked by a step to $0 \mathrm{mV}$ with a single exponential function.
A

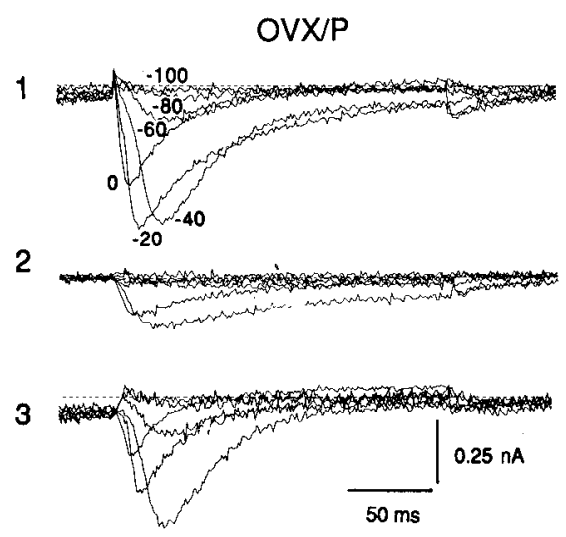

B

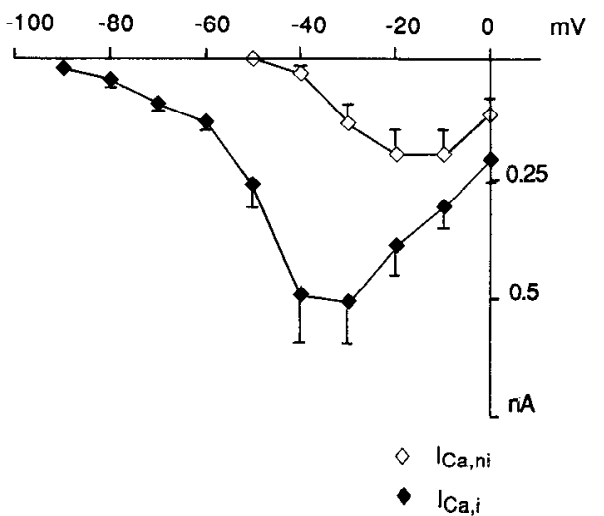

Figure 4. A, Total Ca current (upper panel $)$, and $I_{\text {Ca,ni }}$ and $I_{\text {Ca.i }}$ as obtained according to the protocol shown in Figure 2 in a CA1 pyramidal cell of a rat treated with progesterone at the day of the experiment; the rat did not receive estradiol prior to the progesterone treatment. $B$, Current-voltage relationship for the $I_{C a, j}$ (solid diamonds) and the $I_{\text {Ca,tii }}$ (open diamonds) in rats $(n=6)$ treated with progesterone only. Symbols represent mean values + SEM $(n$ $=11$ cells). 


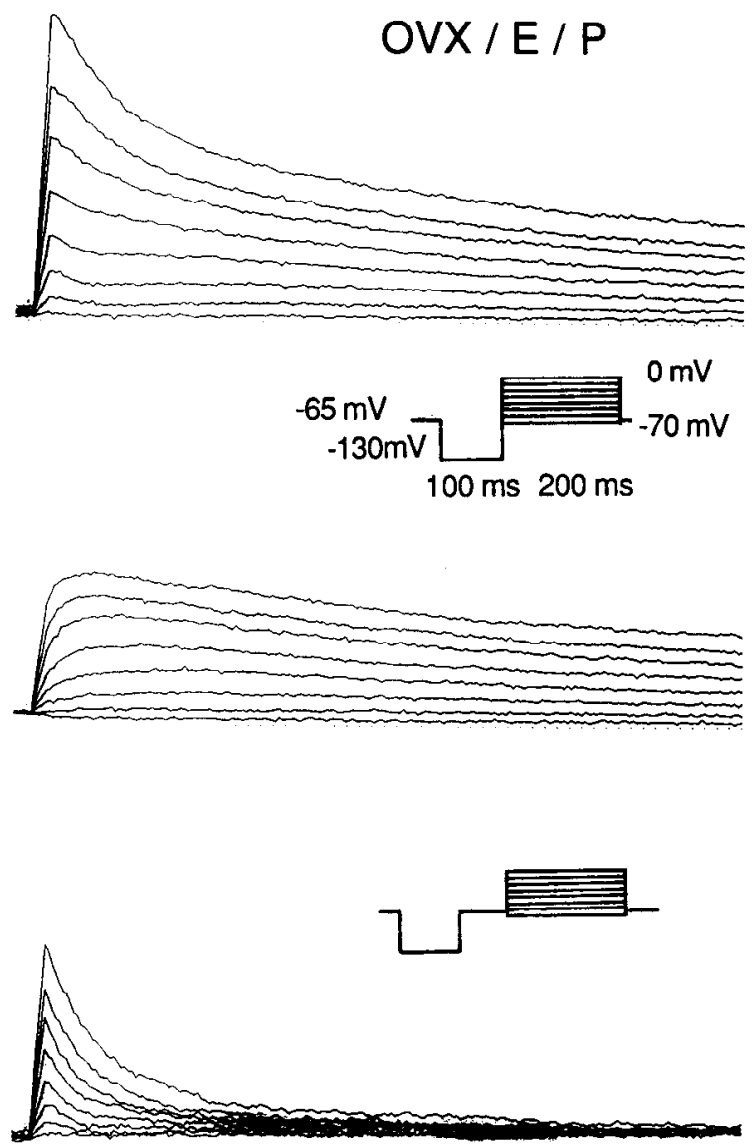

Figure 5. Outward $\mathrm{K}$ currents (upper panel) induced by depolarizing voltage steps from a prepotential of $-100 \mathrm{mV}$ (see inset on the right for voltage protocol). Application of a $75 \mathrm{msec}$ voltage step to $-65 \mathrm{mV}$ between the prepulse and the depolarization resulted in inactivation of the transient component $\left(I_{\mathrm{A}}\right)$ while the sustained phase $\left(I_{\mathrm{K}}\right)$ persisted (middle panel). Subtraction of the sustained current from the overall outward current yielded the $I_{\mathrm{A}}$ in isolation (lower panel). Currents were corrected for leak conductance. Data represent the K currents for a CA1 pyramidal neuron in tissue from an OVX rat (left) and an OVX rat treated with estradiol and progesterone (right).

\section{Discussion}

\section{Current properties}

The present study was initiated to examine if estradiol and progesterone induced changes in dendritic spine density of CA1 hippocampal cells (Gould et al:; 1990; Woolley and McFwen, 1993) are associated with altered properties of voltage gated ion conductances. To answer this question it is essential that the dendritic tree of the CA1 pyramidal cells is relatively intact. This favors the use of hippocampal slices instead of cultured neonatal cells, which may have an atypical morphology, or acutely dissociated neurons, which lack most of their distal dendrites. Given the use of hippocampal slices we preferred recording with low resistance patch electrodes over high resistance microelec- trodes, since the former allows a better voltage control (Marty and Neher, 1983).

Until now, few studies have employed the patch clamp technique in slices to record voltage gated $\mathrm{K}$ and $\mathrm{Ca}$ currents. In earlier reports we and others (Spigelman et al., 1992; Stabel et al., 1992; Karst et al. 1993a,b, 1994) have compared the current properties, as observed with the patch-clamp technique in slices, with currents recorded either with sharp microelectrodes in hippocampal slices or with patch electrodes in cultured or acutely dissociated hippocampal cells. The properties of the $\mathrm{K}$ conductances, that is, of the $I_{\mathrm{A}}$ and the delayed rectifier, were comparable in terms of voltage dependency, kinetics and sensitivity to 4AP and TEA, respectively (cf. Numann et al., 1987). However,

Table 2. General cell characteristics ( $K$ currents)

\begin{tabular}{|c|c|c|c|}
\hline & ovX & OVX/E & OVX/E/P \\
\hline$R_{\text {in }}($ in $\mathrm{M} \Omega)$ & $77.0 \pm 7.3$ & $84.7 \pm 10.0$ & $76.7 \pm 3.5$ \\
\hline$I_{\mathrm{A}} \tau($ at $0 \mathrm{mV}$; in $\mathrm{msec})$ & $18.9 \pm 1.2$ & $17.2 \pm 0.8$ & $18.4 \pm 0.9$ \\
\hline$I_{\mathrm{A}} V_{\mathrm{H}}$ inact. (in $\mathrm{mV}$ ) & $-99.5 \pm 3.1$ & $-101.4 \pm 2.0$ & $-97.9 \pm 1.9$ \\
\hline$I_{\mathrm{A}} V_{\mathrm{C}}$ inact. (in $\mathrm{mV}$ ) & $7.7 \pm 0.8$ & $8.8 \pm 0.6$ & $7.7 \pm 0.6$ \\
\hline$n(N)$ & $17(4)$ & $17(4)$ & $15(4)$ \\
\hline
\end{tabular}

Input resistance and properties of the $I_{\mathrm{A}}$ display no differences between the three experimental groups. 

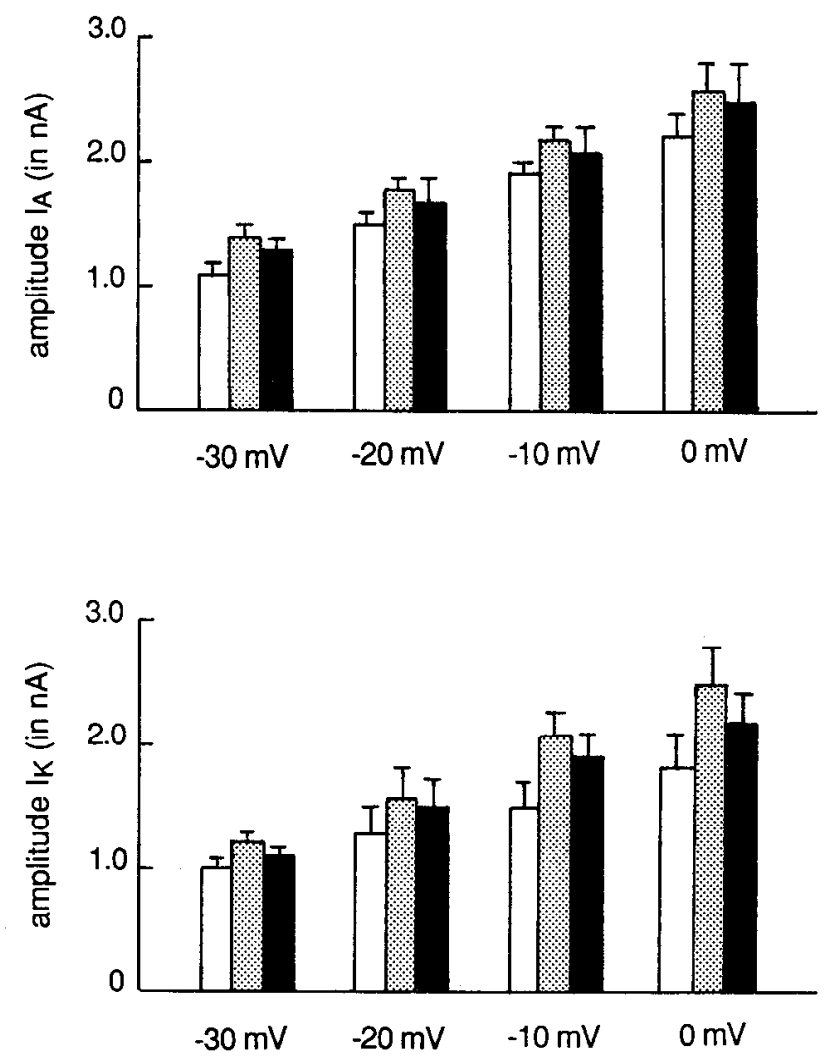

Figure 6 . Average amplitudes (+SEM) for the $I_{\mathrm{A}}$ (upper panel) and $I_{\mathrm{K}}$ (lower panel) induced by voltage steps to $-30,-20,-10$, and 0 $\mathrm{mV}$. Values for the OVX controls (open bars, $n=17$ cells), the estradiol treated group (stippled bars, $n=17$ ) and estradiol/progesterone treated group $(n=15)$ were not significantly different.

contamination of other $\mathrm{K}$ conductances can not be fully excluded. Thus, the presently applied voltage protocol allows some activation of Ca-dependent $\mathrm{K}$ currents (Vreugdenhil and Wadman, 1995); however, the contribution of Ca-dependent $\mathrm{K}$ conductances is probably limited due to the use of a Ca buffering system in the pipette. Contribution of the M-current secms unlikely, since $\mathrm{M}$-currents were rarely observed with the presently used pipette solution and voltage protocol (cf. e.g., Vanner et al., 1993).

For the Ca currents, some discrepancies were observed (Karst et al., 1993a, 1994). First, CA1 pyramidal cells recorded in slices from adult rats displayed a low-threshold type of Ca current, as opposed to dissociated cells (Thompson and Wong, 1991). Second, the amplitude of the sustained high-threshold current observed in slices was smaller than described with other techniques (Kay and Thompson, 1987; Yaari et al., 1987; Meyers and Barker, 1989; Takahashi et al., 1991), while the voltage dependency was shifted toward more negative values. As argued elsewhere (Karst et al., 1993a, 1994) the discrepancies may have been partly caused by the differences in species, recording technique and experimental conditions for the various studies. Thus, the fact that we recorded in cells with a relatively intact dendritic tree may have revealed currents with a dendritic origin, which were not apparent in acutely dissociated or cultured neonatal cells. Clearly, the disadvantage of our approach is the incomplete voltage control over the distal dendrites, so that the amplitude and kinetic properties of currents generated in distal dendrites should be considered with caution. Other discrepancies may have arisen from the present use of adult animals, the recording at $32^{\circ} \mathrm{C}$ and the use of $2 \mathrm{mM} \mathrm{Ca}$ as the charge carrier, as opposed to previous studies. As shown hy Takahashi et al. (1991), particularly lowering the $[\mathrm{Ca}]_{o}$ may shift the amplitude and voltage dependency of $\mathrm{Ca}$ currents toward presently observed values. Additional factors such as the composition of the pipette solution (Kay et al., 1986) may have influenced the present characteristics of the Ca currents. However, a preliminary study using $\mathrm{CsCl}$ and low EGTA $(<1 \mathrm{~mm})$ in the pipette indicates that the kinetic properties of the $\mathrm{Ca}$ currents are not dramatically changed as compared to our present recording conditions (Werkman et al., unpublished observations).

\section{Estradiol and progesterone treatment}

We observed that in tissue from estradiol/progesterone treated OVX rats the amplitude of $\mathrm{Ca}$ currents is increased, compared to the currents in untreated OVX controls; the tested voltagegated K currents were not affected. Gould et al. (1990) have previously shown that treatment of OVX rats with estradiol/progesterone is associated with an increased dendritic spine density in distal dendrites of CA1 pyramidal neurons; the cell body surface does not change (Gould et al., 1990; also observed in the present study by us, in a limited number of cells). Are the steroid dependent changes in electrical properties and inorphology related to each other?

If we assume that the electrical properties of the membrane in newly developed dendritic spines is similar to the already existing membrane, this will result in an expansion of the overall surface area of the spines. Consequently, the input resistance (e.g., at resting membrane potential) will be reduced, the membrane capacity will be enhanced, but the time constant will be little changed. Although a model study (Jaslove, 1992) predicts a reduced length constant, the details of the spine morphology will determine to what extent the effect can be observed in the soma. Unfortunately, experimental verification appeared to be extremely hard in our preparation, since correct estimation of the membrane capacity and length constant was hampered by technical limitations of the patch-clamp technique performed in slices with an upright microscope. However, reliable data about the input resistance (at $-65 \mathrm{mV}$, that is, around resting membrane potential) were obtained. The latter showed no consistent differences for the three experimental groups. Therefore, the data suggest that conductances at resting membrane potential are probably not enhanced after the development of new dendritic spines. Yet, voltage-dependent $\mathrm{Ca}$ (but not $\mathrm{K}$ ) currents, as recorded in the soma, do increase. The enhanced $\mathrm{Ca}$ influx may take place in the newly developed distal dendritic spines, for example, due to steroid-induced expression of $\mathrm{Ca}$ channels. Alternatively, there may be a redistribution of $\mathrm{Ca}$ channels resulting in a relatively increased $\mathrm{Ca}$ influx closer to the cell body. The latter is supported by the fact that the $\mathrm{V}_{\mathrm{H}}$ for steady state inactivation was found to be at a significantly less negative value after estradiol/progesterone treatment: previous studies have shown that the rather negative value for the $V_{\mathrm{H}}$ is caused by the fact that a considerable part of the $I_{\mathrm{Ca}, \mathrm{i}}$ originates in distal dendrites (Karst et al., 1993a). The shift of the $V_{\mathrm{H}}$ to less negative values after steroid treatment can at least partly explain the enhanced $\mathrm{Ca}$ influx seen with our current activation protocol.

The long delay between steroid injection and recording of ion conductances seems to favor a role of intracellular steroid receptors in the development of altered $\mathrm{Ca}$ conductance in CA1 neurons. Involvement of the intracellular steroid receptors has 
also been postulated in earlier studies showing long-term modulation of neuronal excitability in hippocampal and other brain regions by sex steroids (Teresawa and Timiras, 1968; Kawakami et al., 1970; Schiess et al., 1988; Wong and Moss, 1992). These long-term effects are in contrast to fast actions exerted by estradiol via putative membrane receptors (Kelly et al., 1977; Teyler et al., 1980; Nabekura et al., 1986; Smith et al., 1988; Wong and Moss, 1992).

The present data suggest that progesterone at least partly acts through intracellular progesterone receptors induced by estrogen treatment, since increases in Ca current amplitude by progesterone were only observed after estrogen priming. However, we can not exclude that progesterone can also affect ion conductances via other routes. Thus, progesterone displays a high affinity particularly for the mineralocorticoid receptor (M. Carey et al., personal communication). The present experiments were performed in adrenally intact rats where due to the experimental procedure a considerable part of the mineralo- and glucocorticoid receptors are occupied (Reul et al., 1987). Interference of progesterone with the occupation of mineralocorticoid receptors by their natural ligand corticosterone may result in a predominant occupation of glucocorticoid receptors. As found in a previous study in male rats (Karst et al., 1994), Ca current amplitudes recorded under conditions of predominant glucocorticoid receptor occupation are quite small, comparable to the currents observed in the present study for the group of OVX rats which only received progesterone. Also, fast actions of progesterone metabolites via putative membrane receptors (ffrench-Mullen et al., 1993) cannot be ruled out. Progesterone and its metabolites may still be present $4 \mathrm{hr}$ after injection (Karavolas et al., 1976), although it should be realized that the tissue was continuously perfused, in vitro.

Changes in intrinsic membrane properties as a result of differences in plasma levels of estradiol and progesterone may have important consequences for the excitability of CA1 pyramidal neurons, for the efficacy of neuronal networks and for the behavioral functions in which these networks are involved. Increased $\mathrm{Ca}$ conductance during depolarizing inputs may alter the cellular response to transmitters. Whether these changes in intrinsic cell propertics contribute to the previously described stcroid sensitivity of the amino acid mediated input to CA1 neurons (Wong and Moss, 1992) remains unresolved: the response to synaptic stimulation was enhanced after estradiol treatment (progesterone was not tested), while estradiol itself only slightly enhanced $\mathrm{Ca}$ currents in CA1 neurons. Still, enhanced Ca influx through voltage-gated channels in addition to the altered dendritic $\mathrm{Ca}$ homeostasis as a result of the change in dendritic spine density may largely affect the characteristics of local signal transduction (Jaslove, 1992; Guthrie et al., 1992; Müller and Connor, 1992; Koch and Zadok, 1993). Future experiments should provide evidence if natural fluctuations in estradiol and progesterone levels which occur during the estrous cycle are sufficient to regulate voltage gated ionic conductances in the CA1 hippocampal area.

\section{References}

Buterbaugh GC, Hudson GM (1991) Estradiol replacement to female rats facilitates dorsal hippocampal but not ventral hippocampal kindled seizure acquisition. Exp Neurol 11:55-64.

Cintra A, Fuxe K, Harfstrand A, Agnati LF, Miller LS, Greene $U$, Gustatsson JA (I986) On the cellular localization and distribution of estrogen receptors in the rat tel- and diencephalon using monoclo- nal antibodies to the human estrogen receptor. Neurochem Int 8:587595.

ffrench-Mullen JHM, Danks P, Spence KT (1993) Neurosteroids modulate calcium currents in hippocampal CA1 neurons via a pertussis toxin-sensitive G-protein-coupled mechanism. J Neurosci 14:19631977.

Gould E, Woolley CS, Frankfurt M, McEwen BS (1990) Gonadal steroids regulate dendritic spine density in hippocampal pyramidal cells in adulthood. J Neurosci 10:1286-1291.

Guthrie PB, Segal M, Kater SB (1992) Independent regulation of calcium revealed by imaging dendritic spines. Nature 354:76-80.

Hagihara K, Hirata S, Osada T, Hirai M, Kato J (1992) Distribution of cells containing progesterone receptor $\mathrm{mRNA}$ in the female rat diand telencephalon: an in situ hybridization study. Mol Brain Res 14: 239-249.

Jaslove SW (1992) The integrative properties of spiny distal dendrites. Neuroscience 47:495-519.

Karavolas HJ, Hodges D, O'Brien D (1976) Uptake of [ $\left.{ }^{3} \mathrm{H}\right]$ progesterone and $\left[{ }^{3} \mathrm{H}\right] 5 \alpha$-dihydroprogesterone by rat tissues in vivo and analysis of accumulated radioactivity: accumulation of $5 \alpha$-dihydroprogesterone by pituitary and hypothalamic tissue. Endocrinology 98: $164-175$.

Karst H, Joëls M, Wadman WJ (1993a) Low-threshold calcium current in dendrites of adult rat hippocampus. Neurosci Lett 164:154-158.

Karst H, Wadman WJ, Joëls M (1993b) Long-term control by corticosteroids of the inward rectifier in rat $\mathrm{CA} 1$ pyramidal neurons, in vitro. Brain Res 612:172-179.

Karst H, Wadman WJ, Joëls M (1994) Corticosteroid receptor dependent modulation of calcium currents in rat hippocampal CA1 neurons. Brain Res 649:234-242.

Kawakami M, Teresawa E, Ibuki T (1970) Changes in multiple unit activity in the brain during the estrous cycle. Neuroendocrinology $6: 30-48$.

Kay AR, Wong RKS (1987) Calcium current activation kinetics in isolated pyramidal neurones of the CA1 region of the mature guineapig hippocampus. J Physiol (Lond) 392:603-616.

Kay AR, Miles R, Wong RKS (1986) Intracellular fluoride alters the kinetic properties of calcium currents facilitating the investigation of synaptic events in hippocampal neurons. J Neurosci 6:2915-2929.

Kelly MJ, Moss RL, Dudley CA (1977) The specificity of the response of preoptic-septal area neurons to estrogen: $17 \alpha$-estradiol versus $17 \beta-$ estradiol and the response of extrahypothalamic neurons. Exp Brain Res 30:43-52.

Koch C, Zador A (1993) The function of dendritic spines: devices subserving biochemical rather than electrical compartmentalization. J Neurosci 13:413-422.

Loy R, Gerlach JL, McEwen BS (1988) Autoradiographic localization of estradiol-binding neurons in the hippocampal formation and entorhinal cortex. Dev Brain Res 39:245-251.

Majewska MD (1992) Neurosteroids: endogenous bimodal modulators of the GABAa receptor. Mechanism of action and physiological significance. Prog Neurobiol 38:379-395.

Marty A, Neher E (1983) Tight seal whole-cell recording. In: Single channel recording (Sakmann $B$, Neher $E$, eds), pp 107-122. New York: Plenum.

Meyers DER, Barker JL (1989) Whole-cell patch-clamp analysis of voltage-dependent calcium conductances in cultured embryonic rat hippocampal neurons. J Neurophysiol 61:467-477.

Müller W, Connor JA (1991) Dendritic spines as individual neuronal compartments for synaptic Ca responses. Nature 354:73-76.

Nabekure J, Oomura Y, Minami T, Fukuda A (1986) Mechanism of the rapid effect of $17 \beta$-estradiol on medial amygdala neurons. Science 233:226-228.

Numann RE, Wadman WJ, Wong RKS (1987) Outward currents of single hippocampal cells obtained from the adult guinea-pig. J Physiol (Lond) 393:331-352.

Parsons B, Rainbow TC, MacLusky NJ, McEwen BS (1982) Progestin receptor levels in rat hypothalamic and limbic nuclei. J Neurosci 2:1446-1452.

Paul SM, Purdy RH (1992) Neuroreactive steroids. FASEB J 6:23112322.

Pelletier G, Liao N, Follea N, Govindan MV (1988) Mapping of estrogen receptor-producing cells in rat brain by in situ hybridization Neurosci Lett 94:23-28.

Pfaff DW, Keiner M (1973) Atlas of estradiol concentrating cells in 
the central nervous system of the adult female rat. J Comp Neurol $151: 121-158$.

Reul JMHM, Van den Bosch JR, de Kloet ER (1987) Relative occupation of type 1 and type 2 corticosteroid receptors in rat brain following stress and dexamethasone treatment: functional implications. J Endocrinol 115:459-467.

Schiess MC, Joëls M, Shinnick-Gallagher P (1988) Estrogen priming affects active membrane properties of medial amygdala neurons. Brain Res 440:380-385.

Simerly RB, Chang C, Muramatsu M, Swanson LW (1990) Distribution of androgen and estrogen receptor mRNA-containing cells in the rat brain: an in situ hybridization study. J Comp Neurol 294:76-95.

Simmonds MA (1991) Modulation of the GABAa receptor by steroids. Semin Neurosci 3:231-239.

Spigelman I, Zhang L, Carlen PL (1992) Patch-clamp study of postnatal development of $\mathrm{C} \Lambda 1$ neurons in rat hippocampal slices: $\mathrm{mcm}$ brane excitability and K currents. J Neurophysiol 68:55-69.

Smith SS, Waterhouse BD, Woodward DJ (1988) Locally applied estrogens potentiate glutamate-evoked excitation of cerebellar Purkinje cells. Brain Res 475:272-282.

Stabel J, Ficker E, Heinemann U (1992) Young CA1 pyramidal cells of rats, but not dentate gyrus granule cells, express a delayed inward rectifying current with properties of $I_{0}$. Neurosei Lett 135:231-234.

Takahashi K, Ueno S, Akaike N (1991) Kinetic properties of T-type $\mathrm{Ca}^{2+}$ currents in isolated rat hippocampal CA1 pyramidal neurons. J Neurophysiol 65:148-155.

Terasawa E, Timiras PS (1968) Electrical activity during the estrous cycle of the rat: cyclic changes in limbic structures. Endocrinology 83:207-216.
Teyler TJ, Vardaris RM, Lewis D, Rawitch AB (1980) Gonadal steroids: effects on excitability of hippocampal pyramidal cells. Science 209:1017-1019.

Thompson SM, Wong RKS (1991) Development of calcium current subtypes in isolated rat hippocampal pyramidal cells. J Physiol (Lond) 439:671-689.

Vanner S, Evans RJ, Matsumoto SG, Suprenant A (1993) Potassium currents and their modulation by muscarine and substance $\mathrm{P}$ in neuronal cultures from adult guinea pig celiac ganglia. J Neurophysiol 69:1632 1644 .

Vreugdenhil M, Wadman WJ (1995) Potassium currents in isolated CA1 neurons of the rat after kindling epileptogenesis. Neuroscience, in press.

Wong M, Moss RL (1992) Long-term and short-term electrophysiological effects of estrogen on the synaptic properties of hippocampal CA1 neurons. J Neurosci 12:3217-3225.

Woolley CS, McEwen BS (1992) Estradiol mediates fluctuation in hippocampal synapse density during the estrous cycle in the adult rat. I Neurosci 12:2549-2554.

Woolley CS, McEwen BS (1993) Roles of estradiol and progesterone in regulation of hippocampal dendritic spine density during the estrous cycle in the rat. J Comp Neurol 336:293-306.

Woolley CS, Gould E, Frankfurt M, McEwen BS (1990) Naturally occurring fluctuation in dendritic spine density on adult hippocampal pyramidal neurons. J Neurosci 10:4035-4039.

Yaari H, Hamon B, Lux HD (1987) Development of two types of calcium channels in cultured mammalian hippocampal neurons. Science 235:680-682. 